Residual Stress

Distributions in Additively

Manufactured Parts

- Effect of Build Orientation

Prabhat Pant 
Linköping Studies in Science and Technology

Licentiate Thesis No. 1869

\title{
Residual Stress Distributions in Additively Manufactured Parts -Effect of Build Orientation
}

\author{
Prabhat Pant
}

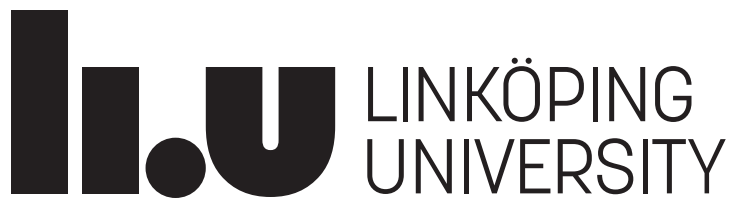

Division of Engineering Materials (KMAT)

Department of Management and Engineering (IEI)

Linköping University, Sweden

Linköping, 2020 
C Prabhat Pant, 2020

Printed in Sweden by LiU-Tryck, Linköping, Sweden, 2020

ISSN -0280-7971

ISBN -978-91-7929-913-2 


\section{Abstract}

Additive manufacturing (AM) of parts using a layer by layer approach has seen a rapid increase in application for production of net shape or near-net shape complex parts, especially in the field of aerospace, automotive, etc. Due to the superiority of manufacturing complex shapes with ease in comparison to the conventional methods, interest in these kinds of processes has increased. Among various methods in AM, laser powder bed fusion (LPBF) is one of the most widely used techniques to produce metallic components.

As in all manufacturing processes, residual stress (RS) generation during manufacturing is a relevant issue for the AM process. RS in AM are generated due to a high thermal gradient between subsequent layers. The impact of residual stresses can be significant for the mechanical integrity of the built parts and understanding the generation of RS and the effect of AM process parameters is therefore important for a broader implementation of AM techniques. The work presented in this licentiate thesis aims to investigate the influence of build orientation on the RS distribution in AM parts. For this purpose, L-shaped Inconel 718 parts were printed by LPBF in three different orientations, $0^{\circ}, 45^{\circ}$, and $90^{\circ}$, respectively. Inconel 718 was selected because it is a superalloy widely used for making gas turbine components. In addition, IN718 has in general good weldability which renders it a good material for additive manufacturing.

Residual stress distributions in the parts removed from the build plate were measured using neutron diffraction technique. A simple finite element model was developed to predict the residual stresses and the effect of RS relaxation due to the separation of the parts and build plate. The trend of residual stress distribution predicted was in good agreement with experimental results. In general, compressive RS at the part center and tensile RS near the surface were found. However, while the part printed in $0^{\circ}$ orientation had the least amount of RS in all three principal directions of part, the part built in $90^{\circ}$ orientation possessed the highest amount of RS in both compression and tension. The study has shown that residual stress distributions in the parts are strongly dependent on the building process. Further, it has shown that the relaxation of RS associated with the removal of the parts from the build plate after printing has a great impact on the final distribution of residual stress in the parts. These results can be used as guidelines for choosing the orientations of the part during printing.

Keywords: Additive manufacturing, residual stress, neutron diffraction, FEM 


\section{Acknowledgments}

First of all, I would like to express my gratitude to my supervisor Prof. Dr. Ru Peng at Division of Engineering Materials(KMAT), Linköping University for believing in me and giving me an opportunity to work in a different field than my previous one. She has been a great mentor and her continuous support throughout the project has been immensely helpful for my journey so far. It is always nice to discuss ideas, results and see them from different perspectives when we have meetings. I will always be in debt to her for my exposure to neutron and X-ray diffraction methods.

I would like to give a special thanks to Prof.Emeritus Sören Sjöström for immense guidance for the FE modeling part. It is always nice to sit and have a discussion with him. I would also like to thank my other supervisors Prof.Dr.Johan Moverare, Prof Dr. Kjell Simonsson for feedbacks and nice discussions. These discussions with all the supervisors have helped me a lot in order to become a better researcher.

I would also like to thank our industrial partners Dr. Seyed Hosseini and Sebastian Proper at RISE IVF, for providing samples and nice discussions on the processing side of the material.

My sincere gratitude to our collaborator Dr.Vladimir Luzin at ANSTO, Australia for being patience and helping us to get the initial beam time, without which the project would not be in the current state as it is now. It has been a great experience working with him.

I would also like to express my sincere thanks to all colleagues at the Division of Engineering Materials for tolerating me so far. Without them it would have been difficult for me to survive cold and dark days of winter and how can I not thank Friday fika (2)

I would like to thank SWEDNESS graduate school for providing the opportunity and atmosphere to learn more about neutron scattering. Through school, I have made really good friends who share common enthusiasm not only in research but also in other aspect of life.

Lastly, a big thanks go to my family who has supported me a lot and all my friends here and back home who were there for me when needed. 


\section{Table of Contents}

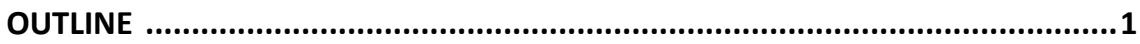

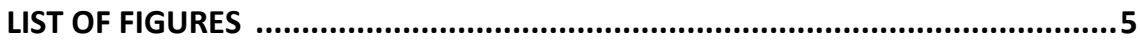

Part I

CHAPTER 1 AIM AND OVERVIEW .............................................................

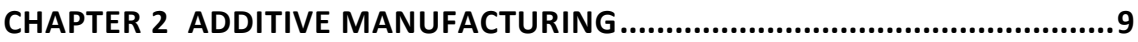

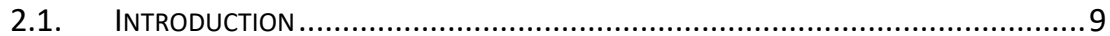

2.2. ApPlication Of THE Additive MANUfacturing:................................... 11

CHAPTER 3 ADDITIVE MANUFACTUIRNG OF METALS ...............................13

CHAPTER 4 RESIDUAL STRESSES: OVERVIEW ........................................ 19

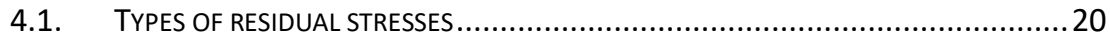

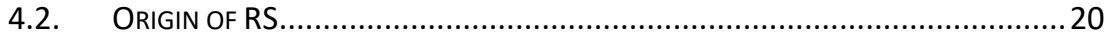

4.3. MEASUREMENT OF RESIDUAL STRESS ................................................... 21

CHAPTER 5 RESIDUAL STRESSES IN METAL ADDITIVE MANUFACTURING .23 CHAPTER 6 NEUTRON DIFFRACTION : TOOL FOR RESIDUAL STRESS

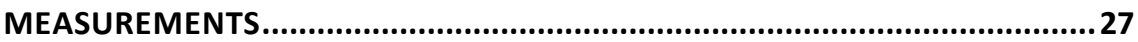

CHAPTER 7 MODELING OF RESIDUAL STRESSES IN ADDITIVE

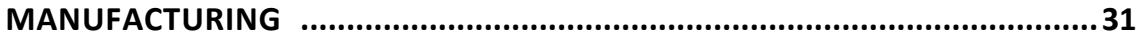

CHAPTER 8 SUMMARY OF APPENDED MANUSCRIPTS AND OUTLOOK .....33

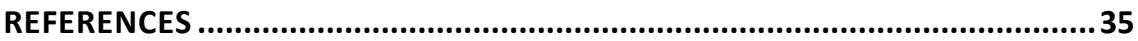

Part II Manuscript Included

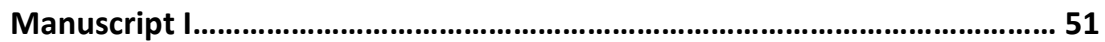

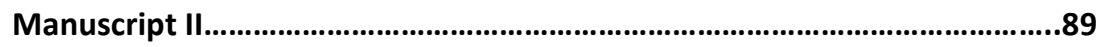




\section{Outline}

This thesis is divided into two parts:

Part I -Background on Additive manufacturing, Residual Stresses, Measurement of Residual stresses

Part II - Appended Manuscripts

Manuscript 1: P. Pant, S. Proper, V. Luzin, S. Sjöström, K. Simonsson, J. Moverare, S. Hosseini, V. Pacheco, R. Lin Peng. Mapping of residual stresses in as-built Inconel 718 fabricated by laser powder bed fusion: A neutron diffraction study of build orientation influence on residual stresses- submitted to Journal of Additive Manufacturing-2020

Manuscript 2: P. Pant, S. Sjöström, K. Simonsson, J. Moverare, S. Proper, S. Hosseini, V. Luzin, R. Lin Peng. A simplified layer-by- layer model for prediction of residual stress distribution in additively manufactured parts - In manuscript.

\section{Paper not included in the thesis:}

P. Pant, R. Lin Peng, J. Moverare, K. Simonsson, S. Sjöström. Influence of build orientation on residual stresses in 3D printed parts Proceeding of AMCTURKEY Conference, 2019 
PART I 


\section{List of Figures}

Fig. 1 Schematic of material extrusion printing process 1) heated nozzle 2) deposited layer 3 ) build platform ............................................................... 10

Fig. 2 Medical implants printed using EBM, Courtesy: Arcam ...........................11

Fig. 3 Satellite bracket. Courtesy: Airbus Space, b) Combustion chamber of rocket engine Courtesy: NASA ........................................................................... 12

Fig. 4 Simple schematic of the powder-based additive manufacturing process. 14 Fig. 5 Sketch for common terminology in Scanning: Contours/borders- Red, Hatching- Green .................................................................................. 15

Fig. 6 Different scanning strategies [6] .................................................. 16

Fig. 7 Influence of different processing parameters on operating window ........17

Fig. 8 Types of residual stresses [10] ............................................................. 19

Fig. 9 Residual stresses in various manufacturing processes [12] ......................21

Fig. 10 Origin of residual stresses in additive manufacturing [16] ....................23

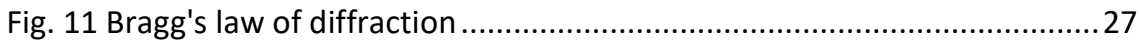

Fig. 13 Typical set up for residual stress measurement at reactor based sources

Fig. 13 Set up at spallation based source (ENGIN-X) [56] ................................30 


\section{CHAPTER 1}

Aim and overview

Additive manufacturing (AM) has seen a vast increase in popularity among different sectors of the manufacturing industry owing to the development of the process and the raw materials for it. The process in the past was linked mainly to polymer material processing and rapid prototyping. Nowadays this technology has seen vast growth in the field of manufacturing material out of metals and has been utilized to manufacture critical components in net shape or near-net shape forms. As additive manufacturing allows for very complex structures to be printed which by traditional manufacturing processes will be either not possible or not feasible in the context of time and money, this technology has found new areas of its applications.

Along with new fields and research into new materials being established for additive manufacturing, there are few underlying problems that have been investigated in the past for a few kinds of systems. Among these problems management of the residual stresses (RS) are one. Residual stresses build up during the processing and are an integral part of the manufacturing which cannot be totally removed but can be managed and controlled using process parameters of the manufacturing.

This thesis aims to provide a bottom-up approach in understanding the connection between residual stresses in laser-based powder bed fusion method with the processing parameters. As the technology of manufacturing parts out of metal powder using a laser as the power source is complex, there are various parameters like laser movement, laser power, laser speed, etc. that can affect the outcome in terms of residual stresses. As it is a 3D process in which parts can be printed in various orientations, so as a first step, the distribution of residual stresses printed in three different orientation has been studied using neutron diffraction method. Also, a simplified finite element method has been developed to predict the stresses distribution and validated with experimental results.

This thesis forms a base for future work which will be focused on different scan strategies, laser power, etc. for control of residual stresses along with mechanical properties study to relate the RS distribution with the processing parameters. 


\section{CHAPTER 2}

Additive manufacturing

\subsection{Introduction}

Additive manufacturing (AM) in general terms is a process of manufacturing parts using the addition of material where needed in contrast to other established manufacturing techniques with which the materials are removed in subsequent steps. According to ASTM F42, AM is defined as "the process of joining materials to make objects from 3D model data, usually layer upon layer, as opposed to subtractive manufacturing methods" [1]. Building of parts is typically realized by layer-wise deposition of a material using a heat source like a laser or an electron beam. This approach of manufacturing has facilitated a more complex and function centric design of products and realization of it as well. The AM technology was developed in the '80s as the tool for rapid prototyping using polymer-based materials. This allowed industries to quickly check their design and modify them if deemed necessary. With time the technology has branched out into other material fields, allowing to process metals and ceramics as well and has also moved forward, from being a tool for rapid prototyping to becoming one of the mainstream methods of manufacturing complex parts.

According to the International Organization for Standardization (ISO), AM processes have been divided into 7 classes [2] as shown below

Material Extrusion: in this process polymer material in wire form is fed through a heated nozzle which can move in three orthogonal directions, with $X$ and $Y$ directions parallel to the deposited layer and $\mathrm{Z}$ parallel to the build direction. In some setup, the nozzle movement is restricted in Z-direction which is compensated by the movement of the base plate upon which the material is being deposited. The polymer materials are heated such that their viscosity becomes low enough for smooth deposition. 


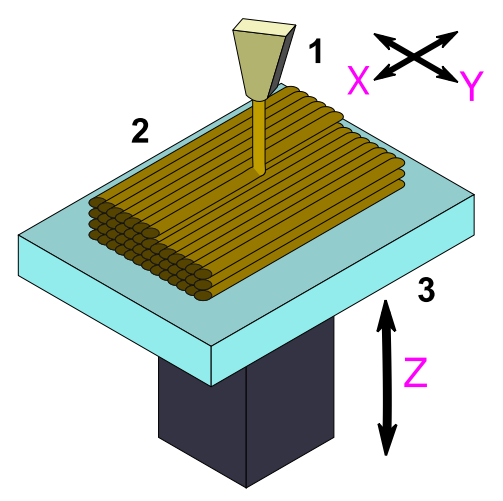

Fig. 1 Schematic of material extrusion printing process 1) heated nozzle 2) deposited layer 3) build platform

Material Jetting: polymer materials are deposited in liquid droplet form rather than wire form when being passed through a heated nozzle. Droplets are deposited on top of each other and they quickly solidify to produce a 3D part

Binder jetting: in this process, both metals and ceramics can be used as the initial materials. For each layer, binders are mixed into the powder in the form of droplets which binds the powder particles together. The binder is removed by burning it off and the part is sintered and later for most of the cases, a second sintering is done at around $80 \%$ of the melt temperature for a denser part. In some cases of ferrous alloys, to create a fully dense part, a liquid metal such as bronze is used as infiltrators [3]. The thermal stresses generated during the process are not so high leading to producibility of large metal parts.

Powder Bed Fusion: both metals and polymers can be used in powder form and energy sources like a laser beam or electron beam are used to melt and fuses the powder particles together to get a certain shape. The shape of each layer is made according to the movement of the heat source and the input given in the CAD model. After the scan of the heat source, a new layer of powder is deposited on top of the fused layer and a similar process is repeated until the entire part is manufactured. As this process involves processing at high-temperature thermal stresses are of great importance and because of it the size of the parts that can be produced is also limited. Based on the design of the part being printed, there might be a need for support structures for holding the part and to limit the distortion of the part. 
Direct energy deposition: it is similar to the powder bed fusion process in many aspects but metals in the form of powder or wire can be used and they are fed directly into the energy source.

Vat polymerization: it is also known as stereolithography where polymers in liquid form are used. Ultraviolet light is shined from above, leading to layer solidification and then the base plate with the part being built is moved into the liquid layer for new layer formation. Depending on the set-up, a part can be built downwards, with the light shining from below and the base plate moving upwards.

Sheet lamination: metal paper sheets are cut out and bonded together in a stack using glue or ultrasonic vibration.

\subsection{Application of the Additive manufacturing}

As the AM technologies have been refined and developed such that they can be used to build net shape or near-net shape parts with good tolerance and properties, they have found or have been explored for applications in many different fields. Two examples are given below.

Medical application:

Most of the implants for joints and dental implants are in complex form. AM has helped to manufacture these kinds of implants with lower weight than original implants (see Fig. 2). Further research on printing scaffolds and stents that can be used during surgery are also going on [4], [5].

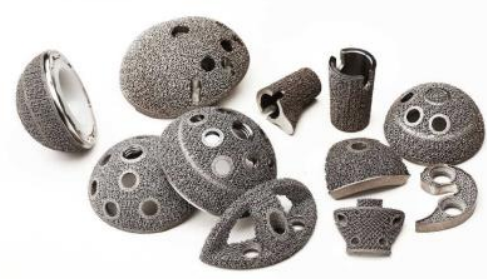

Fig. 2 Medical implants printed using EBM, Courtesy: Arcam 
Aerospace /Automotive Sector:

One of the prominent uses of AM technology can be seen in the aerospace sector. Weight saving without compromising the functionality of the part is the main goal in this sector. The use of AM allows making parts of complex geometry as a result of topological optimization. Further, multiple parts can be combined using this process. Most widely used are in the form of brackets, fuel nozzle, big size components like rocket engine nozzle are also being printed.

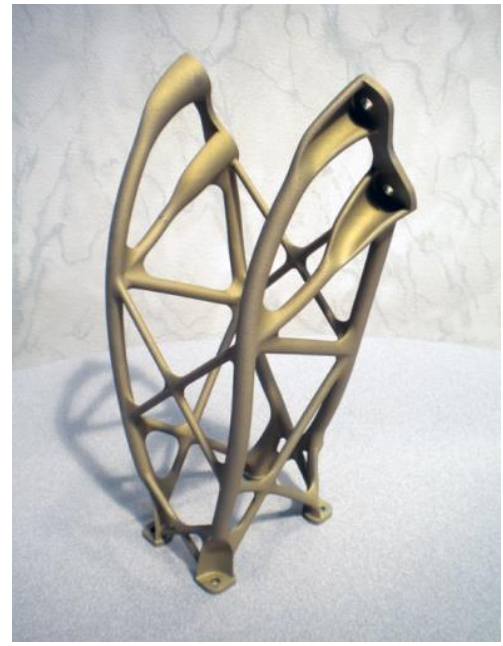

a

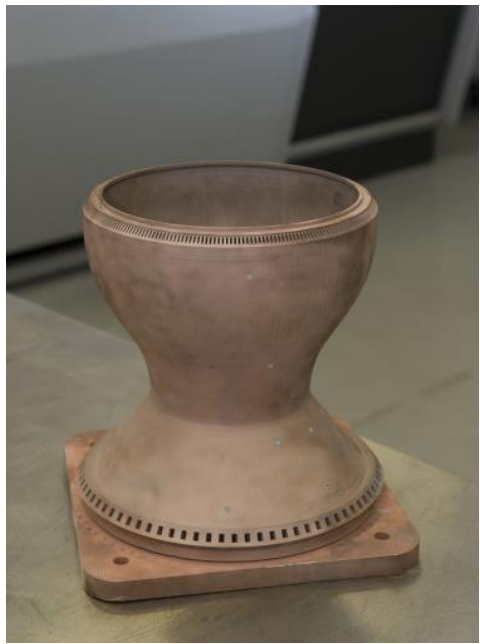

b

Fig. 3 Satellite bracket. Courtesy: Airbus Space, b) Combustion chamber of rocket engine Courtesy: NASA 


\section{CHAPTER 3}

Additive manufacturing of metals

Most of AM metal parts are printed using powder form either by powder bed fusion method or by direct energy deposition. However, the powder bed fusion method is more popular due to good part quality in terms of surface quality and mechanical properties. Here we will discuss about the powder bed fusion method in detail as the work presented in this thesis is focused on parts manufactured using powder bed fusion method.

Selective laser melting is one of the sub-categories of the powder bed fusion processes. As the name suggests, it uses a laser as a primary source for melting the powder layer. A simple schematic of the process is shown below (Fig. 4). At first, the powder is loaded onto the machine in a separate compartment. The powder is then applied to the main chamber as a single layer with the help of a re-coater in the form of a roller or a blade. After each layer is printed, the main chamber moves down and the powder chamber moves up to allow a new layer to be added. This sequence is continued until the part is finished. The entire process is done under an inert gas atmosphere in order to prevent the reaction of the molten metal powder with oxygen. The shape of the part to be printed is governed by the CAD file which is given as input to the machine. The most common file format is the STL format for the 3D printers. Depending upon the material system being used, powder size varies from 30 to 50 microns which govern the layer thickness as well.

The process of printing part out of the metal system is complex as each material behaves differently and the process parameters have to be chosen correctly for each material system. There are a lot of process parameters that need to be finetuned to get the desired characteristic of the built part. These parameters can be primarily categorized into laser parameters (power, spot size, continuous or pulsed, etc.) scan parameters (scan pattern, track length, speed), powder parameters (shape, size, layer thickness, material properties, etc.) temperaturerelated (temperature of powder bed, temperature of base plate, etc.). All of these parameters are intertwined with each other. So their careful choice and tuning of these parameters are required for a particular material system to 
avoid/minimize the formation of defects such as lack of fusion and cracks. For instance, the required laser power increases with an increase in the melting point of the material which also depends upon the absorptivity of the powder bed which in turn is related to powder shape, size and packing density.

Common materials and alloys that have been designed to fit the processing of AM are 316L, Ti64AIVi, In718, etc.

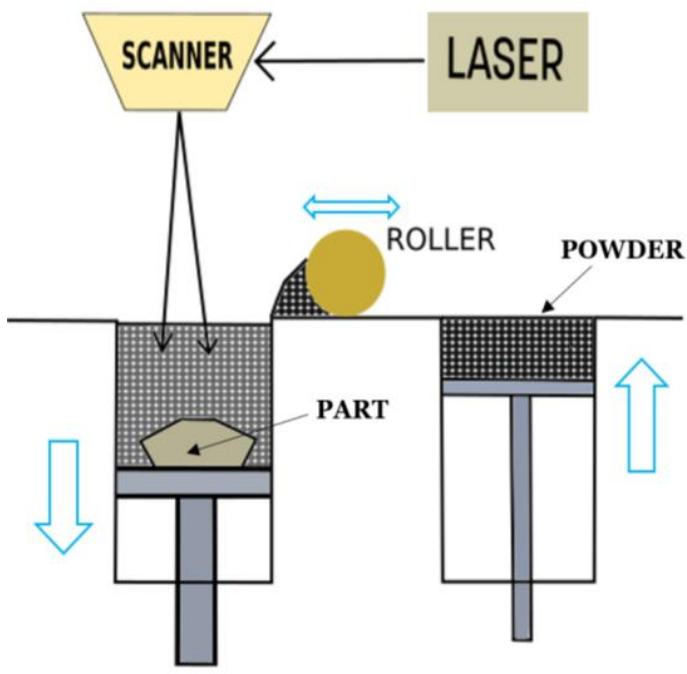

Fig. 4 Simple schematic of the powder-based additive manufacturing process

Common terminologies used in AM are explained below.

Scan strategy:

Scan strategy is basically how the laser is programmed to move along the powder bed to selectively melt a powder layer. There are numerous possibilities to move laser for melting the desired section. For instance, a laser can move in a series of line scans from one end of the part to another, a laser can move in short lengths melting small areas in sequence or random movement of the laser (see Fig. 6). All these possibilities are grouped together in scan strategies. In most of the cases for metals, the outer perimeter of the cross-section layer is melted with different parameters than the bulk and these are commonly referred to as contours or 
borders depending on the equipment being used (see Fig. 5). This is primarily done to get a smoother outer surface and good tolerance. The outcome of the part quality in terms of microstructure and mechanical properties is heavily dependent upon the scan strategies. Research has shown that scan with short vectors, rotation in scans with 67 degrees or 16 degrees, or island scans(see Fig. 6) results in better properties [6], [7].

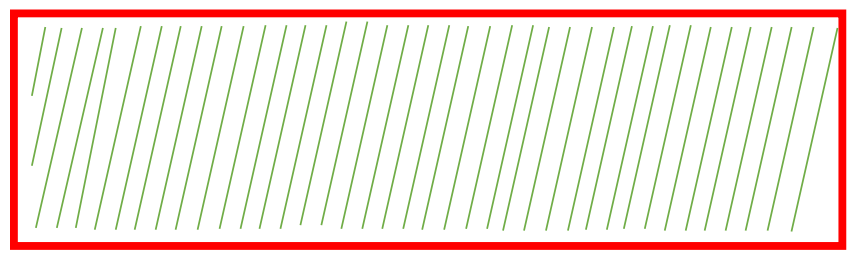

Fig. 5 Sketch for common terminology in Scanning: Contours/borders- Red, Hatching- Green

The energy density (ED): it is the amount of energy that is being applied on the powder by laser with a particular scan speed and hatching distance for a given layer thickness and it is given by:

$$
E D=\frac{\text { Laser power }}{\text { Scan velocity } \times \text { Hatch distance } \times \text { layer thickness }}
$$

$E D$ is one of the main parameters that control the outcome of the part in terms of defects, surface roughness, etc. For most of the cases, ED is kept the same for contouring and hatching but the laser power, speed and hatching distances are different for these processes. 


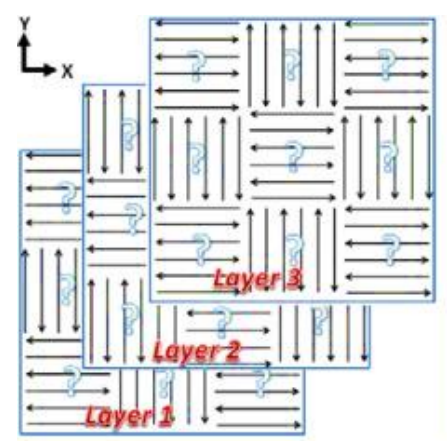

(a) Island scanning

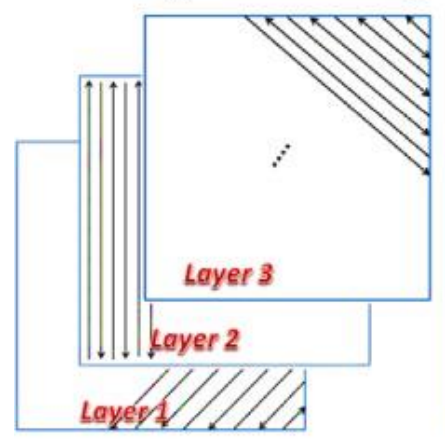

(d) $45^{\circ}$ rotate scanning

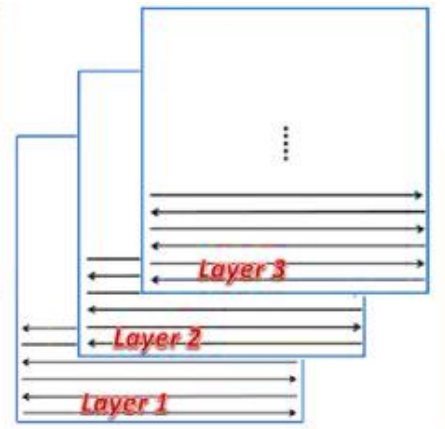

(b) Line scanning

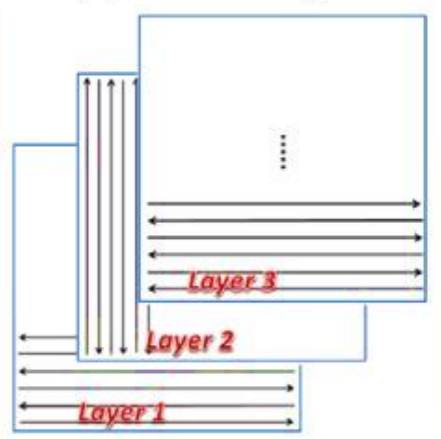

(e) $90^{\circ}$ rotate scanning

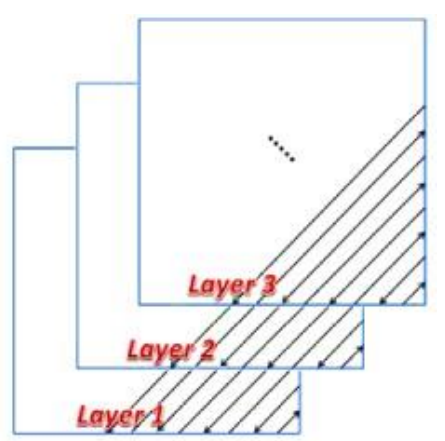

(c) $45^{\circ}$ line scanning

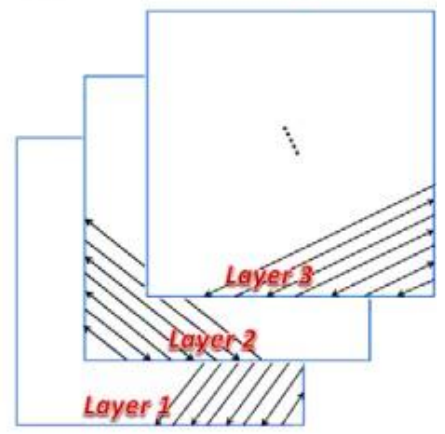

(f) $67^{\circ}$ rotate scanning

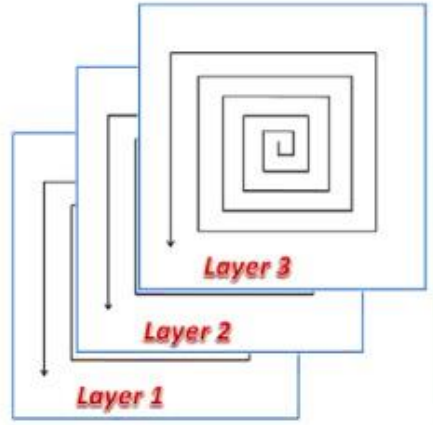

(g) In-out scanning

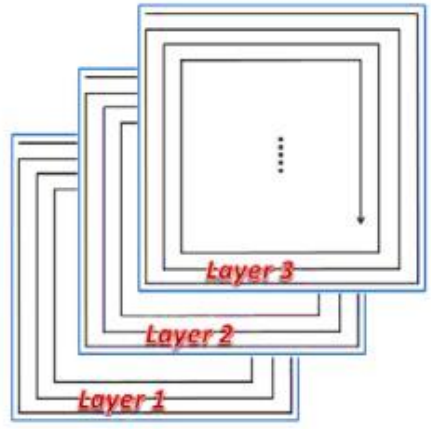

(h) Out-in scanning

Fig. 6 Different scanning strategies [6] 
The following figure (Fig.7) shows the influence of the main processing parameters like laser speed and power to the final part quality [8].

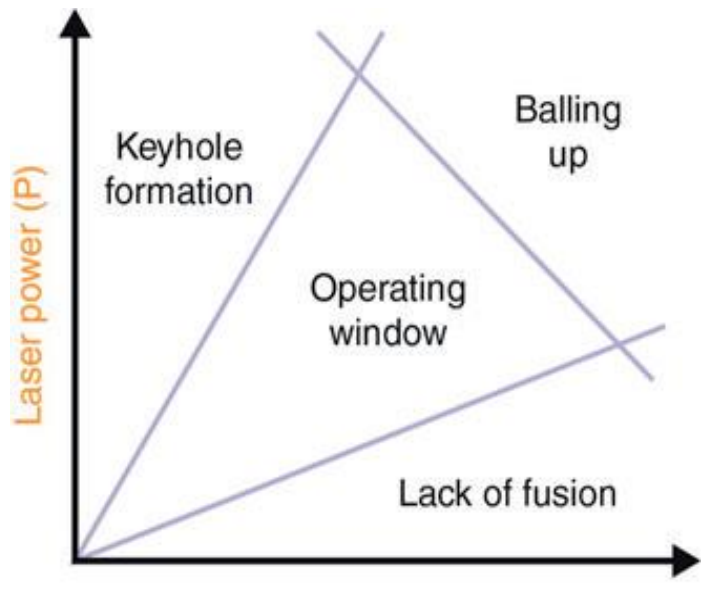

Scanning velocity (V)

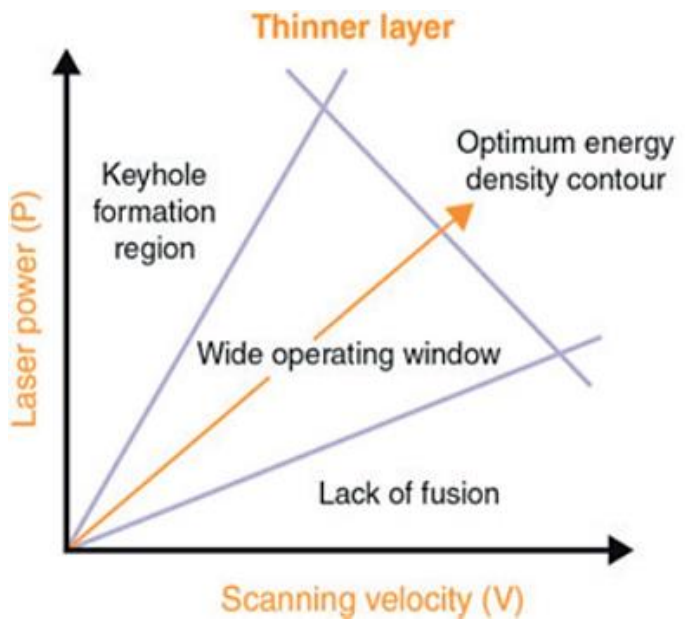

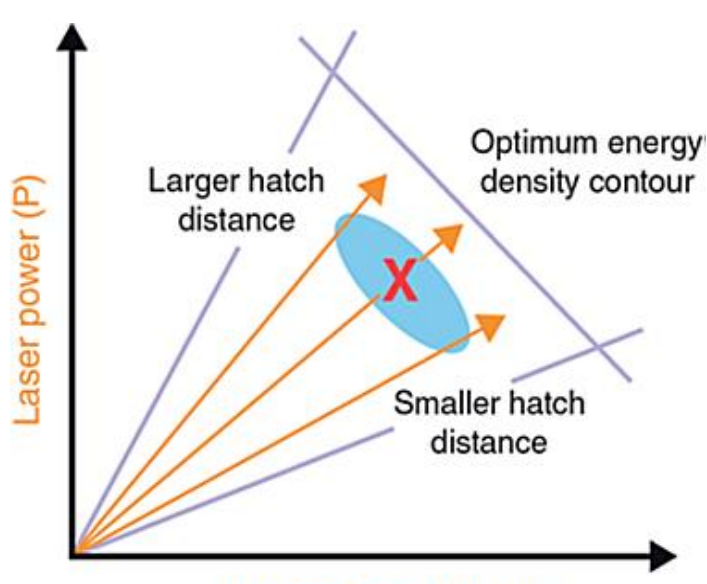

Scanning velocity $(\mathrm{V})$

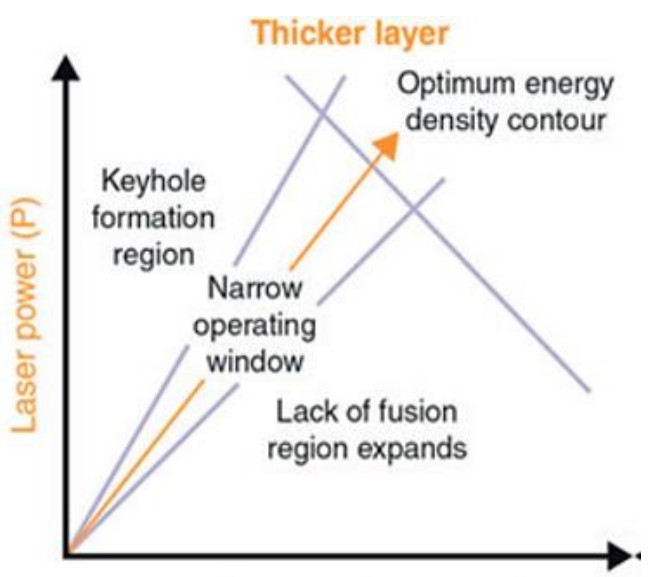

Scanning velocity $(\mathrm{V})$

Fig. 7 Influence of different processing parameters on operating window

From Fig. 7 we can see that at low laser power, having a higher scan speed at the low laser power region will result in lack of fusion whereas increase in laser power at the low laser scan velocity region will result in keyhole formation due to a higher penetration depth of the laser beam, leading to increased porosity and entrapment of inert gases inside the pores. Similarly, the scan strategy, i.e. movement of the laser will also influence the outcome. As seen in Fig. 7 the hatch 
distance will have an influence on the energy density. In most cases, a hatch distance of the same size as the laser spot is generally effective. Also, the thickness of the layer being processed has an influence on the defects that can arise. A thinner layer provides a larger operating window whereas the operating window gets narrow in case of thicker layers (See Fig. 7). Therefore balance on all the fronts of the processing parameters is required to ensure a proper outcome for the part. 


\section{CHAPTER 4}

Residual stresses: Overview

Residual stresses (RS) are stresses that remain locked inside a part which are in an equilibrium state when no external load is being applied. When these selfbalanced stresses are combined with the external loads, depending upon the magnitude, sign, and distribution, their effects on the part performance especially the fatigue resistance may be either detrimental or beneficial. RS can be generated during the processing of parts in connection with the processing techniques used such as heat treatment, cold working, and machining. RS can also develop over the lifetime of the parts under external loading due to local incompatible stains formed by non-uniform plastic deformation [9].

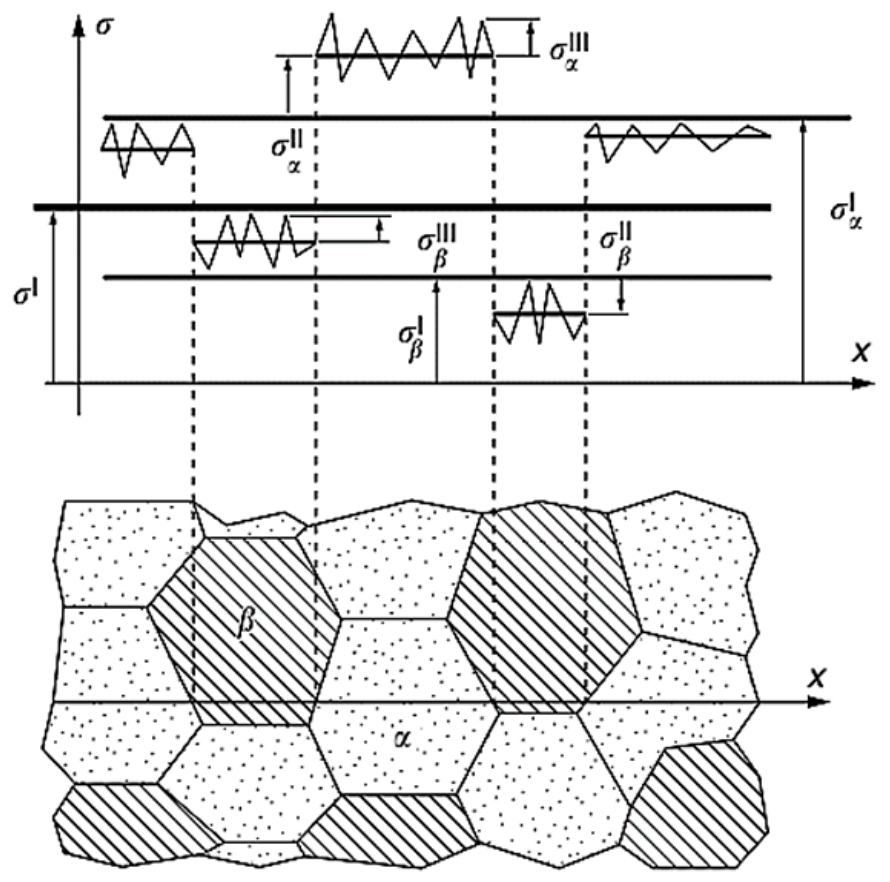

Fig. 8 Types of residual stresses [10] 


\subsection{Types of residual stresses}

Residual stresses are classified by length scale over which they reach equilibrium as schematically illustrated in Fig. 8 [10].

Type I are macro residual stresses that are self-balanced over a length scale of a macroscopic dimension of the sample. They are average residual stress acting in all the phases and crystallites present in the sample. Type II are stresses homogenous within a small domain such as grains or phases. Type III are homogenous within even smaller domains for example around dislocations or point defect. In common terms, both Type II and III are combined and named as micro-stresses. In a real scenario, the actual residual stress at a point in a part is the combination of both macro and micro residual stresses [10].

\subsection{Origin of residual stress}

The origin of residual stresses can vary, depending upon the manufacturing process. In simple terms, we can classify them according to the following [11].

Mechanical RS are generated due to non-uniform plastic deformation. Examples of such manufacturing processes are forging, rolling, bending, drawing, extrusion, etc. Shot peening and cold hole expansion are treatments that can introduce beneficial compressive RS, as shown in Fig. 9. RS of mechanical origin can also be generated during the service of the component. In some cases, they are imposed to create a certain stress distribution which will enhance the part performance.

Thermal RS are a result of non-uniform heating or cooling. They are formed due to non-uniform temperature distributions during processing such as welding, casting, and quenching. Thermal RS are significant for many AM processes including the laser powder bed fusion, which involves local heating and cooling.

Transformation RS are related to local density changes due to phase changes in processes like chemical surface treatments and heat treatment. 


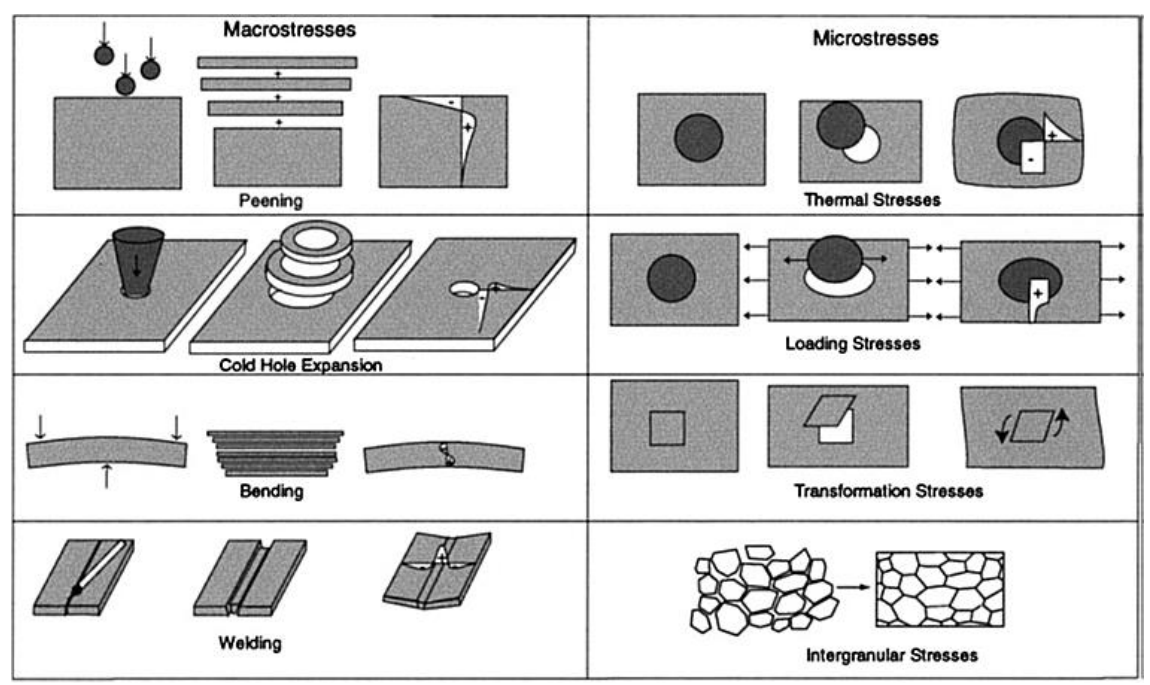

Fig. 9 Residual stresses in various manufacturing processes [12]

Levels and distribution of the RS can cause local yielding and plastic deformation as well. As these stresses are in equilibrium, they are mostly ignored during the product design phase. When external loads are applied, then the influence of residual stresses are realized and depending upon the magnitude and sign, they can be contributing factor for performance enhancement or depreciation. For example, when tensile residual stresses are present at the surface of the component under fatigue loading conditions these tensile stresses will help cracks to form at the surface and to grow, resulting in failure. Failure of the sample can be far below the expected load regime. For these reasons, it is important to understand the mechanism of residual stress formation and to control their levels and distributions in a component. In the case of AM, a higher level of RS can lead to distortions, cracks in the parts, premature delamination of the part from the base plate during part building [13]-[15].

\subsection{Measurement of residual stress}

As discussed, earlier knowledge of the residual stress levels and distribution is necessary in order to be sure about the component's mechanical behavior. There are various methods that have been developed to measure these stresses. We can place them in two categories, namely destructive techniques and nondestructive techniques. Hole drilling and core drilling fall under the category of a destructive technique whereas diffraction-based techniques ( $\mathrm{X}$-ray, neutron), 
ultrasonic, magnetic methods fall under the non-destructive category. The work presented in the thesis is focused on the use of diffraction-based techniques in particular neutron diffraction so this will be discussed in detail in Chapter 6 . 


\section{CHAPTER 5}

Residual stresses in metal additive manufacturing

As the powder-based additive manufacturing is gaining traction, the issue of residual stress management and control is getting more and more complex. With the design freedom that additive manufacturing brings to the table and with a wide selection of processing parameters, the need for systematic approaches to study these stresses is more prominent. As the process of additive manufacturing is a layer up approach, there are significant differences in the temperature between already printed layers on a base plate and the new layer, this mismatch is one of the main reasons for the residual stress formation in metal additive manufacturing, especially for laser powder bed fusion (LPBF) process (see Fig. 10). In the electron beam melting (EBM) process, the temperature of the base plate is maintained at a high level, which leads to a much smaller temperature gradient, and thus very low levels of residual stresses are expected. However, LPBF is more popular due to that a wide variety of materials can be processed using it, in opposite to EBM where the material has to be conductive in nature.

a

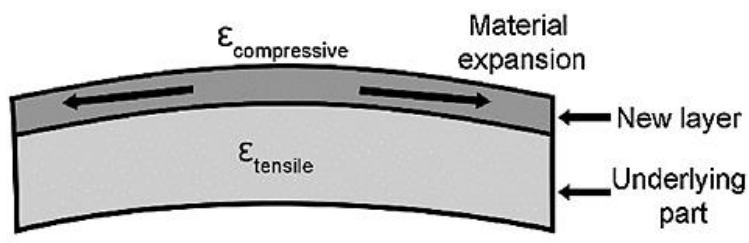

b

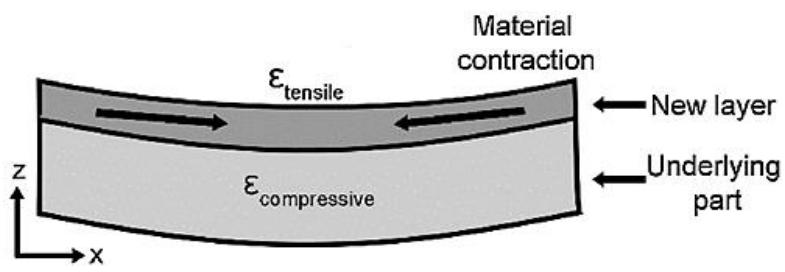

Fig. 10 Origin of residual stresses in additive manufacturing [16] 
As seen above in Fig. 10 for a simplified case, when an entirely new layer is melted simultaneously and deposited, the temperature of the new layer is higher than the underlying part which was cooling uniformly in $Z$ direction (building direction) which will cause expansion in the new layer but this expansion is hindered by the lower layer resulting in compressive stress in the new layer and tensile stresses in the layer beneath ( Fig. 10a ). As soon as the heat source is removed the new layer will start to cool quicker than the underlying part can accommodate, which results in tensile stresses in the new layer and compressive stress in the lower layer (Fig. 10b ) [17]. This is a simplified case where the entire layer is considered to be added instantaneously. However, in reality, a heat source is used to selectively melt material in the layer with the help of a scan strategy. This further complicates the residual stress distribution, especially the in-plane stress distribution, as the temperature also varies within the layer. Very high cooling rates, of the order of $10^{3}$ to $10^{8} \mathrm{~K} / \mathrm{s}$ [18], are observed in the laserbased process, which induces steep thermal gradient and in turn often leads to a very high level of residual stress [19], which in some cases can be close to the material's yield strength. This complex nature of residual stresses has a strong correlation with the processing parameters such as laser power speed and scan strategy, the material properties, and the geometry of the part being printed. There has been research on the residual stress's dependency on the processing parameters and it has been reported by several authors that the top and bottom portions are in tension and the central region are in compression [17], [20]-[23]. Also for the in-plane distribution, it has been reported that the stresses in the longitudinal direction of the laser beam motion are higher than in the transverse direction due to non-uniformity in contraction during cooling [21], [24]-[26].

Among other factors that influence the RS distribution except the laser parameter is the printing orientation of the part. Only a handful of studies has been done to see the correlation between the printing orientation and the RS levels and distribution [27]-[30]. Printing orientation will change the RS distribution because in different orientation the boundary condition for the heat dissipation will be different. It has been found that the part that are built with a greater area in contact with the base plate shows a lower level of RS when compared to the part with exact same geometry printed with a smaller area in contact with the base plate when they are removed from the base plate. Detail about the orientation dependence can be found in the manuscript-I appended in this thesis. A general trend of the tensile residual stress near the surface and 
compressive in the bulk has been reported in various works both experimentally and with the help of modeling [31]-[35].

The following table (Table 1) summarizes the general dependency of residual stress on a few main processing parameters as reported in various literature sources.

Table 1 Dependency of residual stresses on processing parameters

\begin{tabular}{|l|l|}
\hline Parameter & Effect on RS \\
\hline Scan speed & $\begin{array}{l}\text { Higher scan speed --- lower RS [19], } \\
{[24],[36]-[38]}\end{array}$ \\
\hline Source power & $\begin{array}{l}\text { Higher power ---higher RS [37], [39], } \\
{[40]}\end{array}$ \\
\hline Rescan/ pre-scan & Lower RS [17], [23], [41], [42] \\
\hline Pre-heating of base plate & Higher temperature-lower RS [17], \\
& {$[24],[36],[43]-[49]$} \\
\hline Scan orientation & Effects RS distribution and magnitude \\
& {$[17],[26],[28],[41],[46],[50]-[53]$} \\
\hline
\end{tabular}




\section{CHAPTER 6}

Neutron diffraction: Tool for residual stress measurements

Diffraction based techniques have been utilized for measuring residual stresses since a long time ago. By diffraction, the interatomic distances are measured and then converted into elastic strains, from which stresses are calculated using Hook's law. In the case of measuring residual stresses inside a component, the neutron diffraction technique is favored over the X-ray diffraction technique as neutrons penetrate much deeper into a component than X-rays due to its weaker interaction with atoms in the component. On the other hand, X-ray diffraction can be used to get information about the surface stresses. Furthermore, high energy $\mathrm{X}$-rays, with relatively good penetration power and often very high beam brilliance, can be used for measuring stress distributions in thinner components.

When a beam of neutrons or X-rays is shined on the component diffraction occurs following Bragg's law. As Fig. 11 shows, when the waves scattered by the atomic planes, the inter-planar spacing, and the scattering angle satisfy the Braggs condition, a diffraction peak will form from constructive interference. Bragg's law is given below:

$$
n \lambda=2 d_{h k l} \sin \theta_{h k l}
$$

where $\lambda$ is the wavelength of the radiation used, $d_{h k l}$ is the inter-planer distance of $h k l$ planes, and $\theta$ is the incident angle for the radiation.

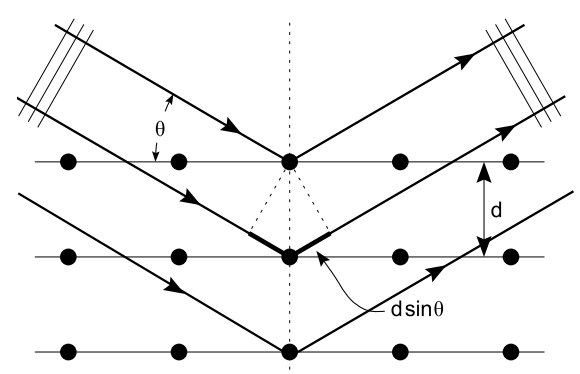

Fig. 11 Bragg's law of diffraction 
In order to get complete information about the residual stress state at the location of interest, strains are to be measured in at least six directions to get a complete strain tensor. However, in practice, measurements are often performed to derive stresses along the principal directions of stresses or in the three orthogonal sample directions if the principal axes are unknown for the sample.

From neutron diffraction measurement, diffraction peaks are obtained and peak fitting is done to extract the inter-planer distance at the location of the interest. These measured inter-planer distance can be used as an internal strain gauge for the material. In order to calculate the strains, a representative sample that can be used as a stress-free sample is also measured. The value of the inter-planar distance for this stress-fress sample, $d_{0}$, is used to convert the measured interplanar distances of the sample into strains using

$$
\varepsilon=\frac{\left(d-d_{0}\right)}{d_{0}}
$$

As the lattice spacing can only change elastically it is an elastic strain that is always measured. However, the strain might be a resultant of macro- and microstresses.

Hook's law is used to convert the strains into stresses as shown in Eq.3.

$$
\sigma_{i j}=\frac{E_{h k l}}{1+v_{h k l}}\left(\varepsilon_{i j}+\frac{v_{h k l}}{1-2 v_{h k l}} \varepsilon_{q q} \delta_{i j}\right)
$$

where,

$\sigma_{i i}-$ stress calculated for a direction

$E_{h k l}$ - Elastic coefficient for $h k l$ plane

Vhkl- Poisson's ratio for $h k l$ plane

In the case of neutron diffraction, thermal neutrons with a wavelength between 0.5 to $4 \AA$ [10] are typically used for residual stress measurement. Nuclear reactor-source based diffractometers such as KOWARI [54] used in the current thesis project are often monochromatic, meaning that neutrons with only one 
selected wavelength are used. This restricts the measurements to only one lattice plane family at a time. Careful selection of neutron wavelength and $h k l$ planes for measurement are necessary in order to measure the macro type residual stress. For FCC material (311) or (111) plane is recommended and for BCC (110) or (211) plane is recommended for measurement of the macro-stresses as they are less sensitive to intergranular strains [55].

Another consideration of the use of $h k l$ planes is the shape of the neutron gauge. Beam slit and detector slit are used to define the probed (gauge) volume of measurement in a component, see Fig. 13. To have a similar spatial resolution in all measurement directions along which stress variation may exist, a $2 \theta$ of approximate $90^{\circ}$ is preferred to have a cube-shaped gauge is preferred.

In a spallation source based neutron diffractometer where neutrons of different wavelengths are being generated in pulses, a number of different lattice plane families can be measured simultaneously. Usually, two sets of detectors are placed opposite to each other such that two strain orthogonal components can be measured simultaneously at $2 \theta$ of approximate $90^{\circ}$. A standard set up of a spallation based engineering diffractometer can be seen in. Details about the analysis of strains and thus stresses using spallation source can be found elsewhere [10], [55]

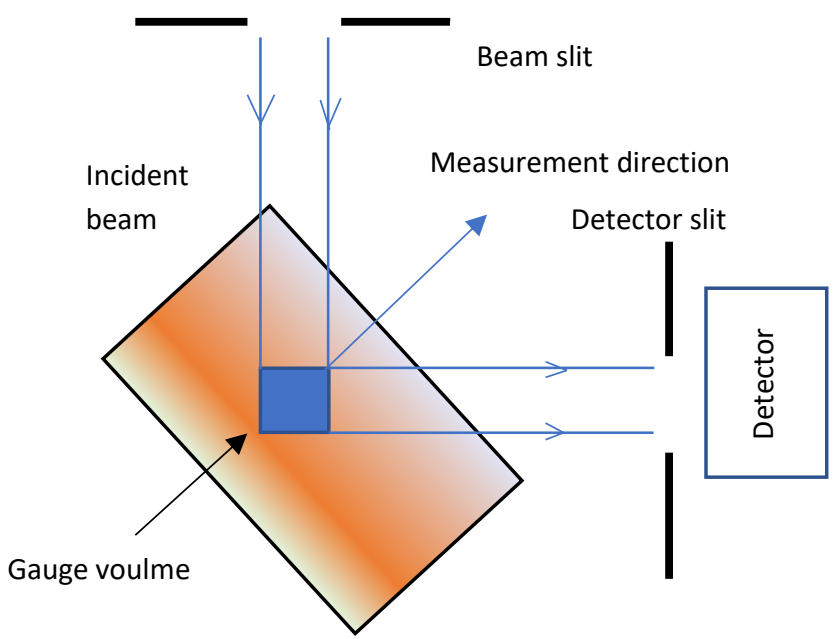

Fig. 12 Typical set up for residual stress measurement at reactor based sources 


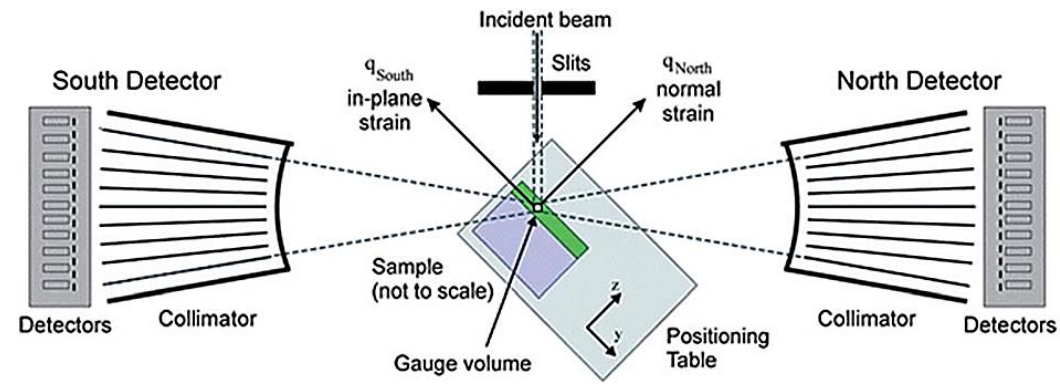

Fig. 13 Set up at spallation based source (ENGIN-X) [56] 


\section{CHAPTER 7}

Modeling of residual stresses in AM

Performing a residual stress measurement with non-destructive or destructive techniques is not always feasible technically or economically. In the case of additive manufacturing, due to various variables that can influence the outcome as discussed in Chapter 3, the trial and error method to get a good processing parameter is not always feasible. Various research has been conducted in order to capture different aspects of the process. Previous research works on the prediction of residual stress in AM has been mostly focused on the use of heat sources modeling and using laser movement strategies into the simulations [57][60]. Fu and Guo [61] have presented a layer-wise simulation of the temperature field with laser movement. Similarly, Childs and Badrossamay, Cheng, Shrestha and Chou [62], [63] have investigated the influence of the different scanning strategies in the temperature field and stresses. Bugera and Lombera [64] initially presented the simulations for sintering for a single track processing and reported information regarding the temperature change, sintering depth, density distribution, etc. Similarly, Ma and Bin [65] proposed a model for thermal stress evolution due to temperature distribution and the associated distortions for a single layer with different scanning strategies. Denlinger, Irwin and Michaleris [66], [67] have investigated into thermomechanical stresses using elastoplastic analysis using quiet element technique and validated the model with experimental investigations. Similarly, the impact of heat on the residual stresses and displacement has been reported by Michael F. Zaeh and Branner [68] through the use of a thermomechanical model using heat as the load. There are numerous other work that has been carried out in the filed for laser interaction with powder, melt pool simulation etc. however, they are not relevant to the macroscopic residual stress formation due to the size of the part being built is far greater than the localized zone studied.

Most of the work discussed earlier is either limited to a 2D model or limited to one layer simulation and to adapt these models into a real part will be computationally demanding. Few of the models, such as the ones presented by Denlinger, Irwin, and Michaleris [67] and Michael F. Zaeh and Branner [68] have been able to predict the residual stress distribution but these kinds of models 
also take into account of the laser movement and use heat as a load and require substantial computational time.

A simplified model based on an approach of layer-wise activation of elements and using temperature as the load is presented in manuscript II appended in the thesis. This simplified model assumes isotropic thermal and elastic behavior of the material. It also uses an isotropic linear hardening behavior based on the von Mises equivalent stress. Instead of using the size of real layers, combined layers containing a number of real layers are activated in sequence. The time for which the load is applied is calculated based on the laser scanning strategy used and the time for re-coater to apply a new layer of powder and movement of the part into the base plate is also accounted for. For the heat loss, simplified boundary conditions of radiation and convection are applied.

The simplified model aim is to predict the stress distribution trends for more complex parts. The model has been validated and is in good agreement with experimental analysis. 


\section{CHAPTER 8}

Summary of appended manuscripts and outlook

Manuscript I- Mapping of residual stresses in as-built Inconel 718 fabricated by laser powder bed fusion: A neutron diffraction study of build orientation influence on residual stresses

This paper primarily deals with residual stress distribution in L-shaped parts printed in different orientations named horizontally build (HB), Vertically build (VB), built at a 45-degree angle (45B). Residual stresses in these samples were measured using neutron diffraction method at selected four (4) cross-sections after they were removed from the base plate. Displacements of the parts, when removed from the base plate, was also measured using a laser scanner system. For all the parts measured, there is a general tendency of tensile residual stress near the surface of the part and compressive towards the bulk. It has been observed that part printed horizontally has the least stress in comparison to other build orientations in all the directions and has the highest displacement when removed from the base plate. Similarly, part built-in vertical orientation has high levels of residual stress when compared to others in all directions. For VB sample residual stress measure in building direction is greater than the inplane stresses. Results from the experiment were compared to a simplified finite element model that was set up for prediction of residual stress and the results from the model is in good qualitative agreement with the experiment. 


\section{Manuscript II- A simplified layer- by- layer model for prediction of residual stress distribution in additively manufactured parts}

This paper deals with a set up of a simplified thermo-mechanical FE tool to predict the residual stress with layer-wise element activation and application of uniform temperature to the entire layer as a load. Model uses a combined layer technique where 10 real layers of the parts are combined into one and activated in sequence using a stress-free element technique. The model has been implemented to L-shaped geometry printed in two different orientations and the results were compared to neutron diffraction results. Magnitudes of the residual stresses predicted from the model are higher than the measured ones. However, the trend of the stress distribution is similar to that of experimentally measured one. The model is also able to predict the relaxation and stress redistribution that occurs in the part when it is removed from the base plate. It has been observed that part with a greater area of contact with base plate results in significant stress relaxation and redistribution than the part with a smaller area of contact with the base plate. This model can be further enhanced to incorporate other process parameters such as laser scan strategy, speed, etc. as well.

\section{Future Work}

For future work, based on the current results, an investigation into the combination of different scan strategies for the reduction of residual stresses for vertically built (VB) sample will be performed mainly using the neutron diffraction technique and modeling of these scan strategies will also be performed. Similarly, another important aspect of the RS i.e. influence on mechanical behavior will also be investigated in combination with microstructure analysis for the parts built with different scan strategies. 


\section{REFERENCES}

[1] ASTM 52921, "Standard Terminology for Additive Manufacturing Coordinate Systems and Test Methodologies," ASTM Int., 2013.

[2] ISO, "Additive manufacturing - General principles - Part 2: Overview of process categories and feedstock," ISO 17296-22015, 2015.

[3] Z. C. Cordero, D. H. Siddel, W. H. Peter, and A. M. Elliott, "Strengthening of ferrous binder jet 3D printed components through bronze infiltration," Addit. Manuf., vol. 15, pp. 87-92, May 2017.

[4] D. Carluccio et al., "Additively manufactured iron-manganese for biodegradable porous load-bearing bone scaffold applications," Acta Biomater., 2020.

[5] A. G. Demir and B. Previtali, "Additive manufacturing of cardiovascular CoCr stents by selective laser melting," Mater. Des., vol. 119, pp. 338350, Apr. 2017.

[6] B. Cheng, S. Shrestha, and K. Chou, "Stress and deformation evaluations of scanning strategy effect in selective laser melting," Addit. Manuf., vol. 12, pp. 240-251, Oct. 2016.

[7] H. Ali, H. Ghadbeigi, and K. Mumtaz, "Effect of scanning strategies on residual stress and mechanical properties of Selective Laser Melted 
Ti6Al4V," Mater. Sci. Eng. A, vol. 712, pp. 175-187, Jan. 2018.

[8] M. Saunders, "X marks the spot - find the ideal process parameters for your metal AM parts," vol. 44, no. 0, pp. 1-11, 2019.

[9] G. S. Schajer and C. O. Ruud, "Overview of Residual Stresses and Their Measurement," in Practical Residual Stress Measurement Methods, Chichester, UK: John Wiley \& Sons, Ltd, 2013, pp. 1-27.

[10] M. E. Fitzpatrick and A. Lodini, Analysis of Residual Stress by Diffraction Using Neutron and Synchrotron Radiation, vol. 14. 2003.

[11] P. J. Withers and H. K. D. H. Bhadeshia, "Residual stress. Part 2 - Nature and origins," Mater. Sci. Technol., vol. 17, no. 4, pp. 366-375, 2001.

[12] P. J. Withers and H. K. D. H. Bhadeshia, "Residual stress part 1 Measurement techniques," Materials Science and Technology, vol. 17, no. 4. IOM Communications Ltd., pp. 355-365, 2001.

[13] P. Mercelis and J. Kruth, "Residual stresses in selective laser sintering and selective laser melting," Rapid Prototyp. J., vol. 12, no. 5, pp. 254-265, Oct. 2006.

[14] L. N. Carter, C. Martin, P. J. Withers, and M. M. Attallah, "The influence of the laser scan strategy on grain structure and cracking behaviour in SLM powder-bed fabricated nickel superalloy," J. Alloys Compd., vol. 615, pp. 338-347, Dec. 2014. 
[15] M. F. Zaeh and G. Branner, "Investigations on residual stresses and deformations in selective laser melting," Prod. Eng., vol. 4, no. 1, pp. 3545, Feb. 2010.

[16] J. L. Bartlett and X. Li, “An overview of residual stresses in metal powder bed fusion," Addit. Manuf., vol. 27, no. February, pp. 131-149, 2019.

[17] P. Mercelis and J.-P. Kruth, "Residual stresses in selective laser sintering and selective laser melting," Rapid Prototyp. J., vol. 12, no. 5, pp. 254265, 2006.

[18] D. Gu et al., "Densification behavior, microstructure evolution, and wear performance of selective laser melting processed commercially pure titanium," Acta Mater., vol. 60, no. 9, pp. 3849-3860, May 2012.

[19] W. E. King et al., "Observation of keyhole-mode laser melting in laser powder-bed fusion additive manufacturing," J. Mater. Process. Technol., vol. 214, no. 12, pp. 2915-2925, 2014.

[20] E. R. Denlinger, "Thermomechanical Model Development and In Situ Experimental Validation of the Laser Powder-Bed Fusion Process * * Should note that some content from this chapter was recently published: Denlinger, Erik R., et al. "Thermomechanical model development and in ," in Thermo-Mechanical Modeling of Additive Manufacturing, vol. 16, Elsevier, 2017, pp. 215-227. 
[21] R. J. Williams, C. M. Davies, and P. A. Hooper, "A pragmatic part scale model for residual stress and distortion prediction in powder bed fusion," Addit. Manuf., vol. 22, pp. 416-425, Aug. 2018.

[22] J. Ding et al., "Thermo-mechanical analysis of Wire and Arc Additive Layer Manufacturing process on large multi-layer parts," Comput. Mater. Sci., vol. 50, no. 12, pp. 3315-3322, Dec. 2011

[23] B. Vrancken, V. Cain, R. Knutsen, and J. Van Humbeeck, "Residual stress via the contour method in compact tension specimens produced via selective laser melting," Scr. Mater., vol. 87, pp. 29-32, Sep. 2014.

[24] A. Hussein, L. Hao, C. Yan, and R. Everson, "Finite element simulation of the temperature and stress fields in single layers built without-support in selective laser melting," Mater. Des., vol. 52, pp. 638-647, 2013.

[25] C. Li, J. F. Liu, X. Y. Fang, and Y. B. Guo, "Efficient predictive model of part distortion and residual stress in selective laser melting," Addit. Manuf., vol. 17, pp. 157-168, Oct. 2017.

[26] Y. Liu, Y. Yang, and D. Wang, "A study on the residual stress during selective laser melting (SLM) of metallic powder," Int. J. Adv. Manuf. Technol., pp. 1-10, 2016.

[27] A. Salmi, G. Piscopo, E. Atzeni, P. Minetola, and L. Iuliano, "On the Effect of Part Orientation on Stress Distribution in AlSi10Mg Specimens 
Fabricated by Laser Powder Bed Fusion (L-PBF)," Procedia CIRP, vol. 67, pp. 191-196, 2018.

[28] A. S. Wu, D. W. Brown, M. Kumar, G. F. Gallegos, and W. E. King, "An Experimental Investigation into Additive Manufacturing-Induced Residual Stresses in 316L Stainless Steel," Metall. Mater. Trans. A Phys. Metall. Mater. Sci., vol. 45, no. 13, pp. 6260-6270, 2014.

[29] L. Mugwagwa, D. Dimitrov, S. Matope, and T. Becker, "A methodology to evaluate the influence of part geometry on residual stresses in selective laser melting," in International Conference on Competitive Manufacturing, 2016, no. December, pp. 133-139.

[30] B. Vrancken, V. Cain, R. Knutsen, and J. Van Humbeeck, "Residual stress via the contour method in compact tension specimens produced via selective laser melting," Scr. Mater., vol. 87, pp. 29-32, 2014.

[31] B. Ahmad, S. O. van der Veen, M. E. Fitzpatrick, and H. Guo, "Residual stress evaluation in selective-laser-melting additively manufactured titanium (Ti-6Al-4V) and inconel 718 using the contour method and numerical simulation," Addit. Manuf., vol. 22, pp. 571-582, 2018.

[32] L. Bass, J. Milner, T. Gnäupel-Herold, and S. Moylan, "Residual Stress in Additive Manufactured Nickel Alloy 625 Parts," J. Manuf. Sci. Eng., vol. 140, no. 6, p. 061004, 2018. 
[33] Y. Liu, Y. Yang, and D. Wang, "A study on the residual stress during selective laser melting (SLM) of metallic powder," Int. J. Adv. Manuf. Technol., vol. 87, no. 1-4, pp. 647-656, Oct. 2016.

[34] K. An, L. Yuan, L. Dial, I. Spinelli, A. D. Stoica, and Y. Gao, “Neutron residual stress measurement and numerical modeling in a curved thin-walled structure by laser powder bed fusion additive manufacturing," Mater. Des., vol. 135, pp. 122-132, 2017.

[35] T. Thiede et al., "Residual Stress in Selective Laser Melted Inconel 718: Influence of the Removal from Base Plate and Deposition Hatch Length," Mater. Perform. Charact., vol. 7, no. 4, p. 20170119, May 2018.

[36] G. Vastola, G. Zhang, Q. X. Pei, and Y. W. Zhang, "Controlling of residual stress in additive manufacturing of Ti6Al4V by finite element modeling," Addit. Manuf., vol. 12, pp. 231-239, 2016.

[37] T. Mukherjee, V. Manvatkar, A. De, and T. DebRoy, "Mitigation of thermal distortion during additive manufacturing," Scr. Mater., vol. 127, pp. 7983, Jan. 2017.

[38] L. E. Loh et al., "Numerical investigation and an effective modelling on the Selective Laser Melting (SLM) process with aluminium alloy 6061," Int. J. Heat Mass Transf., 2015.

[39] T. Simson, A. Emmel, A. Dwars, and J. Böhm, "Residual stress 
measurements on AISI 316L samples manufactured by selective laser melting," Addit. Manuf., vol. 17, 2017.

[40] G. Vastola, G. Zhang, Q. X. Pei, and Y.-W. Zhang, "Controlling of residual stress in additive manufacturing of Ti6Al4V by finite element modeling," Addit. Manuf., vol. 12, pp. 231-239, 2016.

[41] J. P. Kruth, J. Deckers, E. Yasa, and R. Wauthlé, “Assessing and comparing influencing factors of residual stresses in selective laser melting using a novel analysis method," Proc. Inst. Mech. Eng. Part B J. Eng. Manuf., vol. 226, no. 6, pp. 980-991, 2012.

[42] P. Aggarangsi and J. L. Beuth, "Localized preheating approaches for reducing residual stress in additive manufacturing," 17th Solid Free. Fabr. Symp. SFF 2006, pp. 709-720, 2006.

[43] B. Zhang, L. Dembinski, and C. Coddet, "The study of the laser parameters and environment variables effect on mechanical properties of high compact parts elaborated by selective laser melting 316L powder," Mater. Sci. Eng. A, vol. 584, pp. 21-31, Nov. 2013.

[44] C. Zhao et al., "Real-time monitoring of laser powder bed fusion process using high-speed X-ray imaging and diffraction," Sci. Rep., 2017.

[45] N. E. Hodge, R. M. Ferencz, and R. M. Vignes, "Experimental comparison of residual stresses for a thermomechanical model for the simulation of 
selective laser melting," Addit. Manuf., vol. 12, pp. 159-168, Oct. 2016.

[46] M. F. Zaeh and G. Branner, "Investigations on residual stresses and deformations in selective laser melting," Prod. Eng., vol. 4, no. 1, pp. 3545, 2010.

[47] J. P. Kruth, L. Froyen, J. Van Vaerenbergh, P. Mercelis, M. Rombouts, and B. Lauwers, "Selective laser melting of iron-based powder," J. Mater. Process. Technol., vol. 149, no. 1-3, pp. 616-622, 2004.

[48] L. Van Belle, G. Vansteenkiste, and J. C. Boyer, "Investigation of residual stresses induced during the selective laser melting process," in Key Engineering Materials, 2013, vol. 554-557, pp. 1828-1834.

[49] D. Buchbinder, W. Meiners, N. Pirch, K. Wissenbach, and J. Schrage, "Investigation on reducing distortion by preheating during manufacture of aluminum components using selective laser melting," J. Laser Appl., vol. 26, no. 1, p. 012004, Feb. 2014.

[50] L. Parry, I. A. Ashcroft, and R. D. Wildman, "Understanding the effect of laser scan strategy on residual stress in selective laser melting through thermo-mechanical simulation," Addit. Manuf., vol. 12, pp. 1-15, Oct. 2016.

[51] M. Matsumoto, M. Shiomi, K. Osakada, and F. Abe, "Finite element analysis of single layer forming on metallic powder bed in rapid 
prototyping by selective laser processing," Int. J. Mach. Tools Manuf., vol. 42, no. 1, pp. 61-67, Jan. 2002.

[52] B. Cheng, S. Shrestha, and K. Chou, "Stress and deformation evaluations of scanning strategy effect in selective laser melting," Addit. Manuf., vol. 12, pp. 240-251, Oct. 2016.

[53] Y. Lu et al., "Study on the microstructure, mechanical property and residual stress of SLM Inconel-718 alloy manufactured by differing island scanning strategy," Opt. Laser Technol., vol. 75, pp. 197-206, 2015.

[54] O. Kirstein, V. Luzin, and U. Garbe, "The Strain-Scanning Diffractometer Kowari," Neutron News, vol. 20, no. 4, pp. 34-36, Oct. 2009.

[55] M. T. Hutchings, P. J. Withers, T. M. Holden, and T. Lorentzen, Introduction to the Characterization of Residual Stress by Neutron Diffraction. CRC Press, 2005.

[56] A. Fedrigo, F. Grazzi, A. Williams, S. Kabra, and M. Zoppi, "Phase composition mapping of a 17th century Japanese helmet," J. Anal. At. Spectrom., 2015.

[57] T. Mukherjee, W. Zhang, and T. DebRoy, "An improved prediction of residual stresses and distortion in additive manufacturing," Comput. Mater. Sci., vol. 126, pp. 360-372, 2017.

[58] A. J. Dunbar, E. R. Denlinger, M. F. Gouge, and P. Michaleris, 
“Experimental validation of finite element modeling for laser powder bed fusion deformation," Addit. Manuf., vol. 12, pp. 108-120, 2016.

[59] A. M. Korsunsky, T. Jun, and P. Road, "Eigenstrain Analysis of Redisual Stresses Due To Welding and Post-Weld," Miner. Met. Mater. Soc. - 3rd Int. Conf. Process. Mater. Prop. 2008, PMP III, vol. 2, no. September 2015, pp. 738-743, 2009.

[60] E. R. Denlinger, V. Jagdale, G. V. Srinivasan, T. El-Wardany, and P. Michaleris, "Thermal modeling of Inconel 718 processed with powder bed fusion and experimental validation using in situ measurements," Addit. Manuf., vol. 11, pp. 7-15, Jul. 2016.

[61] C. H. Fu and Y. B. Guo, "Three-Dimensional Temperature Gradient Mechanism in Selective Laser Melting of Ti-6Al-4V," J. Manuf. Sci. Eng. Trans. ASME, vol. 136, no. 6, Dec. 2014.

[62] T. H. C. Childs, C. Hauser, and M. Badrossamay, "Selective laser sintering (melting) of stainless and tool steel powders: Experiments and modelling," Proc. Inst. Mech. Eng. Part B J. Eng. Manuf., vol. 219, no. 4, pp. 339-357, Apr. 2005.

[63] B. Cheng, S. Shrestha, and K. Chou, "Stress and deformation evaluations of scanning strategy effect in selective laser melting," Addit. Manuf., vol. 12, pp. 240-251, 2016. 
[64] G. Bugeda, M. Cervera, and G. Lombera, "Numerical prediction of temperature and density distributions in selective laser sintering processes," Rapid Prototyp. J., vol. 5, no. 1, pp. 21-26, 1999.

[65] L. Ma and H. Bin, "Temperature and stress analysis and simulation in fractal scanning-based laser sintering," Int. J. Adv. Manuf. Technol., vol. 34, no. 9-10, pp. 898-903, Oct. 2007.

[66] E. R. Denlinger, J. C. Heigel, and P. Michaleris, "Residual stress and distortion modeling of electron beam direct manufacturing Ti-6Al-4V," Proc. Inst. Mech. Eng. Part B J. Eng. Manuf., vol. 229, no. 10, pp. 18031813, 2015.

[67] E. R. Denlinger, J. Irwin, and P. Michaleris, "Thermomechanical Modeling of Additive Manufacturing Large Parts," J. Manuf. Sci. Eng., vol. 136, no. 6, p. 061007, 2014.

[68] M. F. Zaeh and G. Branner, "Investigations on residual stresses and deformations in selective laser melting," Prod. Eng., vol. 4, no. 1, pp. 3545, Feb. 2010. 
Part II 


\section{Papers}

The papers associated with this thesis have been removed for copyright reasons. For more details about these see:

http://urn.kb.se/resolve?urn=urn:nbn:se:liu:diva-164108 


\section{FACULTY OF SCIENCE AND ENGINEERING}

Linköping Studies in Science and Technology, Licentiate Thesis No. 1869, 2020

Department of Management and Engineering

Linköping University

SE-581 83 Linköping, Sweden

www.liu.se 